\title{
"Intérpretes da história e da cultura": carreiras relioiosas e mediação cultural no Rio Grande do Sul
}

Ernesto Seidl ${ }^{*}$

\begin{abstract}
Resumo: O trabalho aborda as condições de constituição e exercício da função de mediação cultural exercida por agentes vinculados à Igreja católica no Estado do Rio Grande do Sul. Centrado na segunda metade do século XX, são analisados os condicionantes específicos de formação de "especialistas/intérpretes" da "cultura" e da "história" ligados ao fenômeno de imigração e colonização alemã e italiana, e consagrados em tarefas de celebração da "história", da "cultura", da "memória" e do "êxito" social daqueles grupos. Além dos recursos escolares e culturais acumulados por esses mediadores pela inserção em diferentes esferas sociais (religiosa, científico-acadêmica, intelectual, artística), examinam-se as formas e instrumentos simbólicos (publicações, institutos, centros de estudo, cargos, homenagens, editoras) forjados nas disputas pela interpretação dos grupos étnicos oriundos da imigração. O estudo também tem intenção de contribuir para o aprimoramento dos recursos de análise do fenômeno da imigração e colonização (não apenas no Rio Grande do Sul) por meio da ruptura com representações elaboradas com base em referenciais da história, das ciências sociais e da filosofia, representações estas amplamente incorporadas no senso comum acadêmico.

Palavras-chave: Mediação cultural. Imigração. Catolicismo. Intelectuais.
\end{abstract}

* Doutor em Ciência Política. Professor do Departamento de Ciências Sociais e do Núcleo de Pós-Graduação em Ciências Sociais da Universidade Federal de Sergipe (UFS).

Anos 90, Porto Alegre, v. 14 n. 26, p. 77-110, dez. 2007 
"Intérpretes da história e da cultura": carreiras religiosas...

As modalidades de exercício do papel de mediador cultural são variadas e dependem diretamente de condições sociais e históricas específicas de constituição de agentes sociais, mais ou menos especializados, encarregados de tarefas múltiplas ligadas a processos de (re)elaboração identitária e (re)interpretação histórica $\infty$ de grupos sociais aos quais estão vinculados sob vários registros. Assim como a lógica de outras formas de mediação, como a política (CORADINI, 1998b; SILVERMAN, 1971; WOLF, 1971), a lógica da mediação cultural pauta-se pelo fluxo de recursos materiais e simbólicos entre diferentes níveis, esferas e espaços sociais, dinâmica que encontra nos mediadores peça fundamental. Parte das estratégias de legitimação social de determinados grupos sociais, a mediação cultural insere-se entre os esforços de consagração de estilos de vida, práticas sociais e valores culturais empreendida dentro de diferentes esferas, como a intelectual, a acadêmico-científica, a artística, a político-burocrática e a religiosa. Embora não exclusivamente, tal fenômeno está estreitamente associado a contextos históricos e culturais marcados por uma relativa baixa autonomia das esferas sociais (típicos de sociedades "periféricas"), situações em que as lógicas de funcionamento, os recursos e os princípios de legitimação próprios a cada espaço social encontram-se fundidos ou se interpenetram (ANJOS, 2006; CORADINI, 1995).

Este trabalho insere-se nas discussões acerca das condições de constituição e exercício da função de mediação cultural, e tem por referência as relações entre o fenômeno de imigração e colonização alemã e italiana no Estado do Rio Grande do Sul e a emergência de agentes sociais, vinculados à Igreja católica, especializados em tarefas de celebração da "história", da "cultura", da "memória" e do "êxito" social daqueles grupos. O estudo concentra-se em especial na segunda metade do século XX, período de consolidação institucional da Igreja e do sistema universitário no Estado e de afirmação social de parte dos descendentes de "imigrantes" em diversas esferas. Como desdobramentos dessa problemática geral, algumas questões foram privilegiadas na análise.

Anos 90, Porto Alegre, v. 14 n. 26, p. 77-110, dez. 2007 
A primeira delas diz respeito aos condicionantes específicos de formação de mediadores culturais - "especialistas/intérpretes" da "cultura" e da "história" - cuja inserção opera-se pela combinação de recursos acumulados simultaneamente através de carreiras religiosas e acadêmico-intelectuais. Conectado a esse ponto, coloca-se propriamente o problema das intersecções da esfera religiosa com o espaço universitário e intelectual, e as formas de acúmulo da autoridade necessária ao exercício legítimo do papel de mediador socialmente reconhecido; as formas e instrumentos simbólicos (publicações, institutos, centros de estudo, cargos, homenagens, editoras, etc.) forjados nas disputas pela elaboração, definição e interpretação dos grupos étnicos oriundos da imigração; indicações sobre parte do repertório de categorias de percepção social associado àqueles grupos.

Por fim, o estudo tem intenção de contribuir para o aprimoramento dos recursos de análise do fenômeno da imigração e colonização (não apenas no Rio Grande do Sul) por meio da ruptura com representações elaboradas com base em referenciais da história, das ciências sociais e da filosofia, representações estas amplamente incorporadas no senso comum acadêmico.

A partir de uma abordagem mais geral dos recursos sociais e culturais mobilizados na constituição dos "intérpretes da história e da cultura", adentra-se em maior profundidade no exame das condições de existência das modalidades de mediador em pauta com base na exposição dos trajetos sociais de dois casos expoentes: um deles, dedicado a um "especialista" em estudos sobre catolicismo e imigração alemã; e outro, centrado na figura de um dos mais renomados divulgadores da "história" e da "cultura" dos imigrantes italianos no Rio Grande do Sul.

Dentre o conjunto de agentes religiosos dedicados principalmente a tarefas intelectuais (professores, pesquisadores, teólogos) no interior da esfera católica no Estado do Rio Grande do Sul, uma parcela reduzida de indivíduos destaca-se por ocupar posições em que a relação com a "cultura" e seus usos sociais tendem 
"Intérpretes da história e da cultura": carreiras religiosas...

a extrapolar o âmbito estritamente institucional da Igreja. Alocados em centros de produção intelectual universitários e, em geral, detentores de recursos escolares importantes, tais religiosos notabilizaram-se pelo acúmulo de autoridade cultural a partir de uma posição na estrutura eclesiástica favorável a inserções especializadas na divisão do trabalho intelectual da Igreja. Entre os principais temas em que esses religiosos lograram, em graus variados, consagrar-se na condição de "especialistas", dois eixos são predominantes: de um lado, a "história" do catolicismo e de suas estruturas religiosas no Estado; e, de outro, a "história" e os elementos "culturais" envolvidos na imigração e colonização italiana e alemã no extremo sul do país.

Conforme apresentado em outro momento (SEIDL, 2003), esses dois eixos temáticos encontram-se fundidos em abordagens invariavelmente devotadas à imposição do reconhecimento social tanto da "cultura imigrante" - "alemã" e "italiana" notadamente -, quanto de um tipo de catolicismo que, como tratam de demonstrar esses trabalhos, teria sido engendrado no bojo da "cultura" trazida pelos indivíduos daquelas etnias. Se nessa visão o "triunfo" da religião católica é diretamente relacionado ao fenômeno da instalação e reprodução de populações imigrantes não-lusas em partes do Rio Grande do Sul, também a dimensão ética identificada no "êxito" do empreendimento colonizador é objeto privilegiado no material produzido por agentes religiosos que, ao consagrarem as "origens", a "cultura" e o estilo de vida de seu grupo (origem "imigrante européia", religião católica, "comunitarismo"), consagram-se a si próprios pela ascensão à categoria de intérpretes culturais legítimos. ${ }^{1}$ Ou seja, ao lado da celebração social dos trunfos obtidos no campo da religião (legitimidade do catolicismo como confissão dominante, expansão da estrutura institucional - incluindo a rede escolar - multiplicação das "vocações", consagração de religiosos gaúchos no cenário nacional e internacional etc.), todo fenômeno imigratório e seus desdobramentos (elevação do perfil econômico 
e social da "região", ascensão de "imigrantes" às elites políticas e culturais do Estado, entre outros) são apresentados em termos de "saga vitoriosa" na qual os elementos da "história" conferem aos grupos em questão exclusivamente conotações positivas de "empreendedorismo" e "valorização do trabalho", "pioneirismo", "bravura" e até mesmo de certo "heroísmo" social. Portanto, embora essa visão apresente especificidades segundo questões conjunturais e peculiaridades nos itinerários profissionais de seus produtores, trata-se, em todos os casos estudados, da intervenção de uma mesma matriz cultural que é aplicada em todas esferas nas quais esses agentes religiosos estão inseridos.

Dada a quase inexistência de trabalhos acadêmicos que tomem por objeto o próprio conjunto do volumoso material produzido sobre "história da imigração" no Rio Grande do Sul por pessoas comprometidas em alguma medida com o catolicismo e que objetivem, entre outros aspectos, seu contexto de elaboração e o funcionamento do repertório de categorias empregadas, as dificuldades de sua apreciação mais geral são consideráveis. Por outro lado, a parcela consultada em função do grau de consagração e de pertinência informativa, juntamente com material bibliográfico secundário e, em especial, com os depoimentos de um vasto universo de religiosos gaúchos, permitiram que se dispusesse de visualização razoável das percepções dominantes sobre catolicismo, imigração e origem étnica dentro da esfera religiosa. ${ }^{2}$ No entanto, o que está mais diretamente em pauta, aqui, é a constituição de um pólo de produção cultural surgido em torno de agentes religiosos na década de 70 - em notável expansão, desde então especializado nas temáticas referidas que nos interessa abordar. Por essa ótica, o foco da análise encontra-se nas condições sociais e institucionais de existência desses intelectuais e, em especial, nas articulações por eles estabelecidas com outros "produtores culturais" e com instâncias externas à Igreja (universidades leigas, editoras, burocracias, centros culturais) permitindo que se constituíssem como "intérpretes culturais". 
"Intérpretes da história e da cultura": carreiras religiosas...

Assim, o ponto de partida para a investigação foi exatamente o exame dos trajetos sociais e profissionais dos agentes religiosos de maior notoriedade nesse domínio, distribuídos em dois núcleos intelectuais definidos pela origem étnica e o pertencimento institucional religioso: de um lado, os jesuítas estudiosos da imi～gração e do catolicismo "alemães", ligados à universidade mantida

$\infty$ pela própria ordem em São Leopoldo (cidade da região metropolitana de Porto Alegre, conhecida como "berço" da imigração alemã no Estado); e, de outro, o equivalente "italiano", centrado em Porto Alegre em uma editora pertencente aos frades capuchinhos e com estreita relação com uma universidade leiga de Caxias do Sul (situada a $125 \mathrm{Km}$ da capital, na região da Serra), no interior do Estado. O exame das composições de carreira desses intelectuais procurou, assim, apreender não somente os recursos sociais e culturais acionados, os investimentos, estratégias de ascensão e as modalidades de inserção profissional, mas também suas próprias percepções do papel que exercem na esfera religiosa e intelectual. No caso dos intelectuais do grupo "italiano", único caso constituindo, de fato, o que se poderia chamar de um grupo, embora tenha se originado e permanecido em torno de uma "figura-chave", a questão de identificar os mecanismos de formação de uma rede inicial de autores, unidos pela identidade religiosa e por relações de amizade, e a criação e expansão de seus laços com indivíduos situados na esfera editorial, universitária e político-burocrática, ganhou centralidade na análise das condições de sua afirmação e consagração como núcleo cultural.

\section{Percursos escolares e autodidatismo}

Um primeiro aspecto a ser observado quanto às características do grupo de religiosos em pauta é o tipo de recursos culturais que apresentam e as distintas relações de seus membros com a 
esfera acadêmica. Embora sejam todos detentores de títulos escolares superiores outros que os indispensáveis à formação sacerdotal, e atuem ou tenham atuado como professores e/ou pesquisadores em instituições de nível superior em cursos para leigos, tanto o valor desses títulos quanto a área do saber em que se inserem têm variação considerável (ver quadro I em anexo). Tomando em conta os quatro indivíduos que compõem o núcleo básico nos dois pólos mencionados, ${ }^{3}$ vê-se a seguinte divisão entre percursos escolares mais ou menos extensos e especializados: um dos religiosos, graduado em história natural, fez o doutorado e obteve livredocência em filosofia em Porto Alegre e se pós-doutorou em antropologia rural, na Sorbonne; o outro, após o curso de filosofia, fez a teologia na Alemanha, onde também se doutorou em teologia e, ao longo dos anos, realizou quatro pós-doutorados por universidades daquele país, dedicando-se à filosofia medieval. Em contrapartida, os outros dois religiosos em foco obtiveram, um deles, mestrado em educação, pela Universidade Federal do Rio Grande do Sul, e uma "especialização" em "antropologia cultural", pela escola superior dos capuchinhos; e o outro, duas licenciaturas em Letras, em línguas germânicas e línguas latinas, pela PUC de Porto Alegre, realizando estágio de dois anos na Alemanha após a ordenação.

De fato, nos dois primeiros casos trata-se de religiosos de carreira tipicamente universitária, pautada desde o início por investimentos na aquisição de importantes recursos escolares, pelo trânsito em instâncias culturais de prestígio e pela dedicação praticamente exclusiva a atividades de magistério e de pesquisa universitários. Elemento relevante a ser apontado é que ambos, após findarem uma primeira etapa de sua formação escolar, vão ocupar seus primeiros postos no ensino superior na principal universidade do Estado, a Federal do Rio Grande do Sul (UFRGS), e aí terão sua principal inserção profissional até se aposentarem, quando, então, assumem cargos em universidades católicas em Porto Alegre e São 
"Intérpretes da história e da cultura": carreiras religiosas...

Leopoldo. No caso do religioso jesuíta, ele próprio formado pela Universidade Federal em história natural no final dos anos 50, a oportunidade de trabalhar na UFRGS surgiu com um convite para "lecionar antropologia no curso de história". ${ }^{4}$ Em suas palavras, "agarrando a chance" que lhe davam, permaneceria aí por 30 anos, dando aulas de antropologia na graduação e na pós-graduação (leciona a disciplina de título "Religião e Sociedade": minorias étnicas no Brasil", no programa de mestrado em Antropologia Social), e trabalhando simultaneamente, no turno da noite, na universidade da Companhia de Jesus. Após deixar a instituição pública, assume inteiramente funções de ensino e coordenação no curso de pósgraduação em história na universidade católica, dedicando-se à linha de pesquisa "Colonização e Imigração na América Latina".

No caso do sacerdote capuchinho, o ingresso na UFRGS já acontece após seu doutoramento em teologia, ao fim de longa estada na Alemanha, mas também na forma de "convite" (do então diretor do Instituto de Filosofia). O contexto de sua entrada é de reorganização do instituto no final da década de 1960, do qual vários professores haviam sido cassados pelo regime militar, e de "necessidade de ocupar os espaços". Assim, vai disputar a disciplina de filosofia medieval em concurso público, durante o qual sua única concorrente desiste do pleito, segundo narra, ao ver que ele havia trazido a Suma Teológica em latim, e "não havia nenhuma tradução junto". No entanto, além de professor de filosofia, também terá atuação intensa na parte administrativa da instituição, engajando-se na "reconstrução" do Instituto de Filosofia e Ciências Humanas, onde mais tarde viria a ocupar o cargo de diretor, posição em que obtém a aposentadoria por aquela universidade.

Por outro lado, também outro dos intelectuais examinados teve atuação destacada na principal instituição de ensino superior do Estado, como veremos mais detidamente adiante. Por ora, basta apontar que, nesse caso, não se trata de uma carreira exclusivamente centrada na esfera universitária e altamente profissionalizada, pois, 
apesar da longa permanência institucional como professor e, à diferença dos demais casos, nos 12 anos entre sua ordenação como frei capuchinho e o ingresso na Faculdade de Educação da UFRGS, esse religioso desempenhou tarefas diversificadas em formação seminarística e em atividades pastorais. Mesmo assim, foram mais de duas décadas como professor de Psicologia da Educação - cargo pelo qual pôde aposentar-se no magistério -, período em que também obteve o título de mestre em Educação. Portanto, entre os quatro religiosos tomados em conta, apenas um não teve nenhum tipo de passagem por instituições públicas ${ }^{5}$ nem investiu de modo mais intenso em trunfos culturais formais, em que pese todo seu itinerário profissional se tenha dado junto ao sistema escolar (religioso e universitário).

Como se percebe a partir dos percursos escolares desses religiosos, um segundo ponto fundamental diz respeito à nãoprofissionalização nas áreas do conhecimento em que se destacaram e ao claro predomínio de um autodidatismo, apresentado como tal. De fato, embora a posse de diplomas superiores e a inserção profissional em universidades tenda a reforçar nesses indivíduos percepções sobre o exercício da autoridade intelectual com base, em alguma medida, no conhecimento científico, fica evidente a existência de uma concepção das atividades como "especialistas" em termos de aproveitamento de uma "cultura humanística" geral (filosofia, teologia, letras, psicologia, história) que, em parte, é constituída pela própria condição cultural-religiosa e étnica desses indivíduos (a "cultura" alemã e italiana herdada e empiricamente conhecida, como o "domínio" dos idiomas e das "tradições culturais", por exemplo). ${ }^{6}$ Como expressam de modo exemplar as palavras desse sacerdote jesuíta nascido nos anos 20 e atualmente aposentado, "historiador autodidata" e "especialista em história da Igreja", ao explicar as condições que percebe como qualidades para o exercício autorizado de sua função: 
"Intérpretes da história e da cultura": carreiras religiosas...

Estava tudo somado consigo: cursos superiores e, em questão de história, por exemplo, a metodologia científica que eu aprendi e tratava inteiro; era no curso de filosofia, a partir da metodologia para a história. E veja que eu sempre tinha, assim, uma queda especial para a história, não só por notas boas, mas por gosto, por leitura; e depois, também, eu pensei o seguinte: eu ainda cheguei, eu sou dos veteranos que chegam a conhecer mais ou menos oito línguas diferentes; então, isso tudo, toda essa visão filosófica, teológica, científica, literária.

Ou ainda o depoimento desse ex-padre capuchinho, filósofo medievalista, comentando o início de seu envolvimento com o tema da "colonização e imigração italiana" - domínio em que se tornaria um dos nomes mais conhecidos no Estado -, ao ser convidado a apresentar um antigo livro (que "lera quando adolescente"), escrito em dialeto vêneto, sobre um personagem cômico "retratando" o imigrante. Embora sua área fosse a filosofia e a teologia, domínios no qual se especializara, demonstra sua percepção de uma competência cultural mais abrangente e em afinidade com temas tais como a literatura e a "cultura italiana" no Rio Grande do Sul:

Em dezembro de 1974 eu voltava da Europa, onde passara mais de seis anos fazendo doutorado (em teologia) (...). Foram anos valiosos, nos quais muito estudei. Ao retornar, deparei-me com as festividades do Biênio da Imigração e Colonização. (...) Pus-me então a ler novamente uma obra que conhecera aos 15 anos de idade, na qual aprendera bastante do meu parco dialeto italiano, mas à qual, outrora, dera valor apenas pela comicidade. Passados então 20 anos, li-a com outros olhos. Na Europa, havia aprofundado estudos sobre cultura popular, sobre o significado antropológico do folclore, sobre história oral, servira de intérprete para Paulo Freire, cujas obras conhecia muito bem. Não me foi difícil, pois, perceber que o texto de Aquiles Bernardi,

Anos 90, Porto Alegre, v. 14 n. 26, p. 77-110, dez. 2007 
em sua simplicidade, encerrava valores surpreendentes, pouco detectados até então e, em torno deles, escrevi um breve prefácio.

À exceção do professor/pesquisador que se define como "antropólogo" - graduado em história natural, doutor em filosofia (antropologia filosófica) e pós-doutor em "antropologia cultural" -, com inserção acadêmica atual na área de história, os demais fazem questão de ressaltar uma "formação" menos diretamente relacionada a seu itinerário escolar, adquirida por "curiosidade", "interesse próprio" e até por "circunstâncias do acaso", de modo assistemático. Entretanto, a forma de definir a relação com a produção do saber em suas áreas de estudo não é uniforme, a reivindicação explícita de uma postura "científica" restringindo-se aos dois religiosos jesuítas cujos discursos enfatizam uma perspectiva de "cientificidade", de "rigor do método de pesquisa", em suma, de produção de conhecimento objetivo ("como historiador, preciso ter coragem de dizer a verdade, não fugir ou me omitir", "tenho que ser muito amplo em questões de entender").

Já por parte dos dois outros intelectuais, ainda que ambos neguem qualquer pretensão de "cientificidade" ou algum caráter "acadêmico" em seus trabalhos sobre imigração e colonização italiana, as referências recorrentes à "antropologia", à "história" ou à "sociologia" revelam o recurso a um conhecimento escolar e socialmente reconhecido na legitimação de trabalhos de "pesquisa" cujos usos não se encontram na esfera científica. ${ }^{7}$ Assim, de modo complementar à cultura escolar, ou "erudita" - adquirida basicamente dentro do sistema de ensino da Igreja -, e a toda uma bagagem cultural de vivências e contatos com o próprio "objeto" de seus estudos, coloca-se uma apropriação de recursos culturais das ciências sociais favorecendo a manipulação de um vocabulário consagrado nos meios acadêmicos e intelectualizados. É com essa lógica, por exemplo, que se a noção de fazer um estudo "antropológico" significa, na 
"Intérpretes da história e da cultura": carreiras religiosas...

concepção desses indivíduos, fundamentalmente "tratar da vida", "costumes" e "tradições" de imigrantes e descendentes e localizálos num contexto "histórico", a apresentação e comentários sobre os procedimentos de "pesquisa" utilizados são expostos em termos de "história oral", "trabalho de campo", "coleta de material", "metodologia de pesquisa" e vários outros elementos do jargão acadêmico que demonstram a posse de um saber especializado chancelado pela esfera acadêmica.

\section{Modalidades de mediação cultural: dois trajetos profissionais}

Os dois casos aqui apresentados estão longe de dar conta das possibilidades de exercício da mediação cultural, embora grande parte dos recursos e mecanismos identificados seja comum a outros casos. Sua exposição mais detalhada ganha relevância pela riqueza oferecida em termos analíticos. No primeiro caso, trata-se tipicamente do exercício da função de intelectual dedicado primeiramente à consagração de sua instituição religiosa, expandindo em seguida a "área de estudo" à medida que obtinha reconhecimento dentro e fora da Igreja. Membro de uma geração de jesuítas sagrados nos anos 50, formada em um ambiente marcado pela tradição cultural e escolar "alemã", ao lhe ser dada oportunidade (que procurou) de investir na vida intelectual, encarregou-se de representar e reforçar toda uma perspectiva de Igreja e de catolicismo já presente em gerações anteriores de jesuítas germânicos, cujo pensamento resgatou em seus trabalhos de pesquisa e tradução. Em um segundo momento, o foco será posto no caso do frei capuchinho que logrou tornar-se um dos principais nomes entre os "estudiosos" da "história" e da "cultura" italianas no Rio Grande do Sul, homem altamente comprometido com a "memória de sua gente". Interessando-se algo tardiamente pela temática, após vários anos de trabalhos diversos como religioso, decide dedicar-se a esses estudos e encontra condições para iniciar uma série de 
publicações que, em pouco tempo, seriam expandidas com a criação de sua própria editora. A partir de um conjunto de relações pessoais internas e externas à Igreja, esse sacerdote-editor estimulou a formação em seu entorno de um grupo de "pesquisadores", com os quais organizaria a maior coleção de publicações sobre uma etnia no Brasil.

\section{"Um guardião da memória religiosa"}

Décimo terceiro e último filho de um casal de pequenos proprietários rurais da região de Santa Cruz do Sul (cidade "fundada" por imigrantes alemães no século XIX, a 120 quilômetros da capital Porto Alegre), neto de "colonos pioneiros" a se instalarem naquela zona, J. entrou no seminário dos jesuítas em meados dos anos 30, seguindo dois de seus irmãos tornados religiosos pela mesma ordem. Após os estudos iniciais, segue o curso de filosofia no Colégio Cristo Rei, em São Leopoldo, continuando sua formação no Anchieta, de Porto Alegre, época em que realiza dois cursos simultâneos de letras (línguas germânicas e latinas), pela PUC/ RS. Em seguida, retorna ao Cristo Rei para fazer teologia, recebendo a ordenação quatro anos mais tarde, aos 32 anos de idade. Sendo indicado pelos superiores para lecionar língua e literatura nas Faculdades Leopoldenses, solicita, antes, fazer um estágio na Alemanha, onde permanecerá por dois anos. De volta a São Leopoldo, assume então funções docentes na faculdade de Filosofia, Ciências e Letras daquela instituição, futura Universidade do Vale dos Sinos (UNISINOS). É por esse período que afirma ter "começado a pensar que talvez pudesse prestar mais para a Igreja do que ser simples professor de letras", dizendo que "talvez estivesse iludido de ter um preparo também para isso, mas que dava duro". Disposto, portanto, a investir numa carreira oferecendo maiores chances de ascensão pelo reconhecimento intelectual do que a "mera" função no magistério, se apresenta ao seu superior 
"Intérpretes da história e da cultura": carreiras religiosas...

provincial "para escrever, estudar a história, escrever a história dos jesuítas na fase moderna", e lhe diz que, embora fosse um "autodidata na historiografia, achava que tinham que lhe dar um voto de confiança".

Respaldado por sua ordem religiosa, J. iniciará, assim, um longo período de dedicação à "pesquisa", cujos resultados serão difundidos por numerosas publicações em meios de caráter variado, sobretudo em periódicos ligados a faculdades ou universidades católicas na área de história, ciências humanas e filosofia - especialmente a Estudos Leopoldenses, revista da própria universidade jesuíta -, mas também em publicações de caráter institucional religioso, como os jornais e revistas da Companhia de Jesus, da CNBB regional e da arquidiocese de Porto Alegre, ou sem relação direta com a Igreja, na imprensa do Estado e de outras regiões. ${ }^{8}$ Desse modo, a partir das instâncias mais escolares das quais estava em condições de utilizar os instrumentos de divulgação e de legitimação no papel de "historiador oficial" dos jesuítas, J. obteria em pouco tempo reconhecimento mais amplo não apenas dentro da Igreja gaúcha, mas igualmente em diversas outras instituições consagradas da esfera intelectual, tais como o Instituto Histórico e Geográfico do Rio Grande do Sul, do qual se tornou membro ativo.

Veja, eu que sou autodidata, eu recebi esse diploma (oferecido pela UNISINOS, "em reconhecimento ao seu trabalho") e, então, é por causa do que eu fiz pela ciência e também pela historiografia. Eu não esperava isso, porque eu não me preocupo com isso (risos), nem pensava ser homem da Igreja e marcar uma presença nos meios intelectuais, literários e cultos. Eu sou mais ou menos participante de dez instituições diferentes e não estou lá para fazer bonito, não. É para trabalhar, aprender e, sobretudo, para dar uma contribuição. Assim é que eu, autodidata, acho que pude marcar uma presença de igreja, de jesuíta também, no meio desses cursos, ao lado de maçons, ateus, marxistas e também católicos.

Anos 90, Porto Alegre, v. 14 n. 26, p. 77-110, dez. 2007 
Seu forte investimento em pesquisas documentais, incluindo consultas a arquivos em Roma e em Colônia, para a elaboração de "histórias" eclesiásticas locais e regionais representou instrumento central no acúmulo de um capital religioso assentado em uma "cultura" indicando a incorporação e manipulação da "memória" da ordem - trunfo distintivo de relevância considerável. Dentro de suas atividades como "especialista" de história jesuítica no sul do Brasil, J. valeu-se amplamente de expedientes encontrados com bastante freqüência em tarefas de consagração institucional - na Igreja e outras instituições corporativas -, como é o caso dos meticulosos trabalhos de "resgate" e divulgação de traços e relatos biográficos de membros de seu grupo religioso. Embora suas obras de maior efeito nessa área tenham sido as que tornaram conhecidas as "histórias" de "grandes figuras" do clero jesuíta notabilizadas ainda em vida - forma predominante entre esse tipo de estratégia de retraçar biografias edificantes a servirem de exemplo ${ }^{9}$-, não se limitou àquelas, mas tratou de também jogar no sentido inverso de promoção institucional ao "trazer à tona" justamente nomes desconhecidos de sacerdotes "pioneiros" no empreendimento religioso daquela ordem no Rio Grande do Sul, iniciado no século XIX. Com o domínio do idioma alemão, traduziu e publicou grande quantidade de documentos (cartas, notas de viagem, comunicados, diários) escritos por aqueles religiosos contendo suas impressões a respeito da "situação" religiosa, cultural e geográfica encontrada nas terras em que chegavam para prestar serviços religiosos aos imigrantes, servindo-se amplamente desse tipo de material para atualizar e difundir um conjunto de percepções sobre religiosidade e etnia. Através da recriação de um passado longínquo e da identificação de uma continuidade de "propósitos" que "permanecem até o presente", trata-se, entre outras coisas, e como costuma ocorrer em toda história edificante, de forjar uma "tradição" na qual se inscreve uma vasta linhagem de religiosos, cujas figuras e fatos precisam ser conhecidos pelos coirmãos de ordem, mas também por seu entorno social. 
"Intérpretes da história e da cultura": carreiras religiosas...

Se a dimensão consagradora do empreendimento jesuítico no Rio Grande do Sul compõe um eixo básico das percepções contidas no laudatório material compilado, traduzido ou escrito por esse sacerdote, esta se encontra inextricavelmente ligada ao componente étnico-cultural identificado tanto com a ação da Companhia de Jesus naquela região, quanto com o tipo de população que ela atendeu preferencialmente por muitas décadas nas "colônias". Dito de outra forma, a associação entre o tipo de religiosidade trazida pelos jesuítas alemães e cultivada em meio aos imigrantes e descendentes de mesma origem explicaria um "florescimento" (ou "desenvolvimento") que, na verdade, vai muito além do mero aspecto religioso traduzido na imposição de um catolicismo "romanizado" e na multiplicação "vocacional" entre os "de origem" (teuta). De fato, se a "cultura germânica" dos imigrantes - em contraposição à cultura "luso-brasileira" nativa - seria "naturalmente" propícia à recepção do catolicismo pregado pelos jesuítas, o que está em jogo é um esforço mais amplo de reconhecimento social de toda uma visão de mundo que passa, entre outros aspectos, pelas estruturas associativas e comunitárias, o código de ética e o estilo de vida nas "colônias", pela escola paroquial e a imprensa católica e pela formação de uma elite "cultural" e política dentro das escolas jesuíticas de renome.

É sob essa perspectiva, portanto, que está construído o conjunto de "pesquisas" desse intelectual jesuíta, fruto ele próprio, sob todos ângulos, do fenômeno que se propõe "descrever" e "interpretar", tendo alcançado a reputação de "especialista" em imigração alemã. E é nessa condição que dividirá espaço com historiadores "profissionais" em diversas publicações, acadêmicas ou não, abordando elementos da história regional. Assim, por ocasião das celebrações do sesquicentenário da imigração alemã no Rio Grande do Sul, em 1974, produz um dos textos mais representativos de tal percepção da "contribuição teuta" à Igreja católica, do qual transcrevemos alguns trechos: 
[...] À chegada dos jesuítas espanhóis, o exercício prático da religião estava como que extinto no meio luso-brasileiro. [...] Desde a vinda dos jesuítas alemães, em 1849, começou a florescer de fato uma vida católica a partir das duas extensas paróquias de S. José do Hortênsio e S. Miguel dos Dois Irmãos. Sob a direção forte e enérgica de seus pastores espirituais, formou-se, na "mata virgem", uma geração deveras católica, diríamos católica até a medula dos ossos. Assim se tornou a população católica da Colônia Alemã o fermento de uma vida religiosa diferente no Rio Grande do Sul.

Expressão típica dessa religiosidade temo-la na organização ou estrutura paroquial comunitária: fruto da índole germânica e do trabalho pastoral. [...] as pequenas comunidades escolar-eclesiásticas [...] eram o fundamento sobre o qual o missionário pôde construir o edifício de sua ação pastoral. [...] Mais importante ainda é que essa estrutura se tornasse, por assim dizer, herança obrigatória dos católicos teutos e de seus descendentes nas várias migrações internas e até externas.

Como se percebe com clareza, a herança intelectual da ideologia étnico-religiosa sobre a qual se fundou o projeto de restauração católica jesuítica no Estado é reapresentada com todo vigor por esse sacerdote formado em um ambiente altamente favorável à incorporação de uma visão triunfante do empreendimento católico "alemão". No entanto, mais do que propriamente o repertório de noções fundando tais percepções de "regeneração", ou "renovação" da Igreja rio-grandense em termos de oposição culturalreligiosa entre "luso-brasileiros" e alemães, chama-se atenção para as condições de reprodução e reconhecimento de tal discurso através de instrumentos culturais consagrados pela esfera escolar, notadamente aqueles referendados por centros universitários (eventos, publicações), e postos ao alcance de agentes devotados à reprodução simbólica da instituição religiosa. 
"Intérpretes da história e da cultura": carreiras religiosas...

\section{Imigração italiana: "a paixão de cada dia” de um frei capuchinho}

O caso de "exitoso" empreendimento cultural realizado por frei L. durante cerca de três décadas, concretizado na criação de uma editora especializada em "imigração italiana", e de sua consagração como autoridade intelectual no tema traz à tona elementos cuja compreensão interessam aqui por pelo menos duas razões fundamentais. Primeiramente, por revelar uma multiplicidade de recursos sociais e culturais mobilizáveis na composição de uma carreira religiosa bem sucedida, assim como a variedade de inserções sociais e profissionais às quais está atrelada. Com base nas múltiplas posições ocupadas nas esferas religiosa, universitária e intelectual, o exame dos tipos de trunfos e de suas formas de utilização estratégica em momentos distintos do itinerário profissional desse religioso põe em relevo algumas das intersecções do espaço religioso com outros espaços sociais, favorecendo o acúmulo de um importante capital de notoriedade. ${ }^{10}$ Em segundo lugar, por iluminar um aspecto muito marcante no estudo das relações entre o fenômeno imigratório e a estruturação da Igreja católica no Rio Grande do Sul, que é o notável predomínio de agentes religiosos ou próximos àquela instituição na produção bibliográfica sobre "imigração italiana" no Estado. Assim, ao se ter em conta a constituição de um grupo de autores - compartilhando em alto grau uma "origem nas colônias" e uma formação escolar e profissional religiosa - que terão oportunidade de publicar seus trabalhos pela editora dirigida pelo frei capuchinho, pode-se compreender o tipo de perspectiva ou viés "de dentro" que baliza o vasto material em questão.

Segunda geração de "italianos" nascidos no Rio Grande do Sul, frei L. viveu até os 11 anos de idade na zona rural de um pequeno município da "região italiana" na serra gaúcha, quando então 
deixou a pequena propriedade dos pais para entrar no seminário dos frades capuchinhos, situado nessa mesma cidade marcada pela presença daquela ordem desde inícios do século XX. Último filho entre uma prole de sete, afirma ser o único sacerdote do grupo familiar amplo, todos os seus irmãos mantendo-se ligados ao trabalho rural. Findados os estudos prévios à teologia no sistema escolar da ordem espalhado pelo Estado, começa o teologado na pequena cidade de Garibaldi e o conclui na Escola Superior de Porto Alegre, recebendo o sacerdócio ao iniciar a década de 1960. Após cerca de oito anos trabalhando em um seminário menor do interior e também dando aulas de religião em uma escola na capital, é indicado para dirigir o curso de teologia. Em acordo com o pequeno grupo remanescente de alunos que desejavam fazer um trabalho "alternativo", instala-se em uma penitenciária, onde desenvolve atividades variadas com a população carcerária. No início dos anos 70, L. começa simultaneamente uma inserção escolar intensa a partir da aproximação com o curso de Educação da Universidade Federal do Rio Grande do Sul, no qual iniciara pós-graduação em Psicologia Educacional e, à semelhança de diversos outros religiosos católicos nesse período, recebe convite para ser professor naquela faculdade, em seguida fazendo concurso e sendo aprovado "em primeiro lugar". Logo após terminar o mestrado, obtém "livre-docência" em "Antropologia Cultural" pela Escola Superior de Teologia, porém, não chega a fazer a validação do título junto ao Ministério da Educação. Quanto a suas atividades passadas, aponta a docência na UFRGS como a "preferida" e, sobre o fato de um padre trabalhar em uma instituição pública, comenta que sua condição religiosa era valorizada ("na UFRGS, eu era bem quisto por ser padre"). Nessa universidade permanece por mais de vinte anos como professor e diretor-fundador da revista da Faculdade de Educação, até obter a aposentadoria.

Desde os tempos em que trabalhou como formador no seminário menor, frei L. destaca seu "desejo" de "transformar a concepção 
"Intérpretes da história e da cultura": carreiras religiosas...

do sacerdócio e da vida religiosa" de modo geral. Para ele, a vocação não podia se restringir à execução das tarefas diocesanas ou daquelas definidas pelos superiores religiosos, no caso específico do clero religioso. Pelo contrário, sua visão do "novo padre" é justamente a de um homem "integrado na sociedade", com "inserção na vida prática" e "autonomia pessoal", cuja noção de "obediência" não seja "limitante". É a partir daí, lembra frei L., que ele chegou ao "princípio de personalizar a própria ação, de formar o padre personalizado em uma determinada ação e atividade", pondo-o em prática inicialmente com o grupo de seminaristas que vai trabalhar no presídio e o mantendo por "toda a vida".

Religioso afinado com os propósitos da "abertura" conciliar, é convidado por um amigo frei a escrever artigos sobre "fraternidade religiosa" para a revista da CNBB regional, depois reunindo-os em forma de livro e obtendo sua primeira publicação de maior circulação através de uma editora sem vínculos religiosos. As circunstâncias dessa publicação e as conseqüências que tiveram tanto sobre sua futura carreira de escritor e editor quanto sobre a formação de um núcleo de religiosos escritores que encontrariam oportunidade rara de editar seus materiais são algo inusitadas. Segundo frei L., seu contato com o proprietário da editora em questão ("um maçom casado com uma católica") deu-se em um sebo no centro de Porto Alegre, cujo dono tratou de apresentá-los. Tornando-se amigos rapidamente, frei $\mathrm{L}$. pede-lhe que publique a compilação de seus textos, em seguida saindo outra obra sua sobre catequese, "inaugurando-se", assim, a "temática religiosa" nas publicações daquela editora. Valendo-se dessas "boas relações", frei L. lembra que "aproveitou a oportunidade para publicar outros temas, como 'Igreja, divórcio e matrimônio"', traduzido do alemão por um frei capuchinho, acrescentando que "nunca uma outra editora católica publicaria esse tema". No entanto, não apenas escritos seus eram publicados, mas também os de amigos sacerdotes - dentre os quais vários futuros bispos e religiosos de destaque -, que ele "encaminhava 
ao editor", incluindo títulos não exclusivamente associados à religião, como metodologia de pesquisa e psicologia, por exemplo.

\section{O "interesse" pelos "costumes populares", o "resgate da memória italiana" e a criação de uma editora própria}

O redirecionamento que frei L. daria a seus interesses editoriais e que o consagraria na condição de autoridade na área de imigração e colonização italiana ganhou, de fato, impulso a partir dos primeiros anos da década de 1970, quando foi comemorado o centenário da chegada dos primeiros imigrantes italianos ao Rio Grande do Sul. No entanto, o material que serviria de base para seu primeiro livro nessa temática já vinha sendo coletado "há vários anos", oriundo do "profundo interesse" de frei L. pela "cultura popular" na região "italiana”. Assim, já na época do trabalho no seminário, localizado no centro da zona de colonização, o sacerdote havia "despertado para o saber popular", envolvendo-se na criação de cooperativas de trabalhadores rurais e na distribuição de sementes e hortaliças, em seguida passando a catalogar nomes de plantas nativas e seus usos a partir da consulta a anciões locais. É nesse contexto, afirma, que surgiu sua curiosidade sobre os costumes daquelas pessoas, a quem chama de "colonos".

$\mathrm{Eu}$ achei interessante registrar o que eles faziam, o que eles pensavam, e tinha lá um clube pelo qual eu sempre passava pelas quatro horas, todos dias [...] e sempre estavam lá, e tinha uns quantos velhos jogando baralho; aí, eu inventei de gravar histórias com eles, ou como eram os antepassados deles, como eles se recordam da primeira casa, e me interessava muito saber de um tal padre $\mathrm{F}$, que foi pároco em Antônio Prado e depois foi expulso de lá [...].

Entusiasmado com as gravações, frei L. escreve dezenas de textos a partir dos "diálogos" e "informações" coletadas junto 
"Intérpretes da história e da cultura": carreiras religiosas...

àqueles "colonos", remetendo-os para publicação em um jornal de propriedade dos capuchinhos e de ampla circulação nas "colônias italianas". Tais textos não seriam publicados pelo jornal, porém, alguns anos mais tarde, formariam a principal matéria para um livro que marca o início da exploração de amplo filão temático $\infty$ por esse religioso. Como mencionado, a ocasião para sua estréia no domínio da "imigração" foi o biênio comemorativo da colonização italiana (1974-1975), momento em que se promoveu um concurso de monografias sobre o tema. Novamente aí, as relações de amizade estabelecidas por frei L. lhe serviram em algum sentido, pois ele soube de tal certame e foi incentivado a participar por influência do filho do cônsul italiano em Garibaldi - um "italianista" e membro ativo da Igreja (era então presidente da Ordem Terceira) - com quem tinha "muita amizade" e "encontrava regularmente no convento" em Porto Alegre. Mas além dessa razão, frei L. também aponta outro motivo que teria sido determinante para sua decisão de inscrever um trabalho. Trata-se, segundo afirma, de sua "insatisfação" com o tipo de abordagem que encontrara na monografia escrita por um confrade, fruto de uma tese de doutorado em sociologia, defendida em Paris, à qual frei L. tivera acesso e que viria a se classificar em segundo lugar no concurso. No seu entender, estudos acadêmicos naqueles moldes não tinham valor nenhum para o evento ("podiam valer para os intelectuais, mas não para os celebrados; se eu o desse para a minha mãe ler, o que ela diria? Vou dar para o meu irmão, ele nem vai entender o título"). Além disso, via somente ser contada a "história do imigrante vencedor, que montou indústrias etc.", argumentando que "a maioria dos imigrantes não aparecia ali: aqueles que ainda são "colonos"'. Dessa forma, decide retomar as gravações de que ainda dispunha e prepara um texto sobre "vida, costumes e tradições" dos imigrantes italianos, com o qual receberá "menção honrosa" no concurso celebrativo. Conseguindo publicá-lo de forma "barata" por uma editora ligada à Igreja, esse foi o ponto de partida para uma 
série de investimentos "intelectuais" centrados no estudo da "cultura italiana", no qual seu nome se tornaria a principal referência no Estado.

\begin{tabular}{|l|}
\hline $\begin{array}{c}\text { Dando a palavra ao imigrante } \\
\text { Como por acaso, um dia senti-me envolvido pela } \\
\text { imigração italiana e pelos estudos de imigração e co- } \\
\text { lonização em geral. [...] Professor da Faculdade de } \\
\text { Educação da Universidade Federal do Rio Grande do } \\
\text { Sul, desde 1972, na área de Psicologia Educacional, } \\
\text { não estava em minhas cogitações qualquer interesse } \\
\text { por estudos históricos nem referentes à imigração e } \\
\text { colonização. Mas, ao revisar a datilografia do texto de } \\
\text { Manfrói, passou-me a interessar-me o tema e come- } \\
\text { çou a me provocar angústia. Na obra de Manfrói, en- } \\
\text { contrei dois diferentes blocos: uma excelente docu- } \\
\text { mentação oficial e uma mais excelente análise. Na } \\
\text { época, estava lendo as obras de Margareth Mead e Si- } \\
\text { mone de Beauvoir e continuava a me ocupar a mente } \\
\text { a preocupação de que, além dos bons estudos sobre a } \\
\text { imigração, dever-se-ia dar oportunidade a imigrantes } \\
\text { e descendentes de primeira geração a dizerem sua pa- } \\
\text { lavra sobre si mesmos e sua experiência. }\end{array}$ \\
\hline
\end{tabular}

A percepção das possibilidades de expandir as atividades editoriais do grupo de amigos - ao qual servia de intermediador e de investir de modo independente na divulgação de temáticas pouco exploradas, levou frei L. a criar uma editora própria, nas dependências de sua casa, porém com autonomia frente à hierarquia de sua ordem religiosa. Em especial, "o universo do imigrante italiano" - tema praticamente ausente tanto da literatura acadêmica quanto da ficcional editada - afigurava-se uma vertente das mais promissoras ("até então, não tinha nada sobre imigração. Tinha a tese do Manfrói e o livro do Thales de Azevedo"). Único responsável pela escolha dos lançamentos, frei L. podia contar, já de 
"Intérpretes da história e da cultura": carreiras religiosas...

início, portanto, com recursos fundamentais ao empreendimento editorial em que apostava, pois, além da estrutura física, dispunha de uma ampla quantidade de títulos produzidos por seus amigos religiosos em áreas variadas, aos quais se agregariam, sob seu estímulo, novos religiosos dedicados à "imigração" no Estado. É a partir da formação dessa equipe informal de escritores, coordenada por frei L., que nasceria uma coleção exclusivamente destinada à imigração italiana, cujo primeiro título foi o próprio livro de estréia daquele sacerdote-editor sobre o tema.

Esse grupo de autores incentivados por frei L. compunha-se basicamente, à semelhança de seu líder, de sacerdotes ou ex-sacerdotes residentes no interior do Estado ou na capital, de ascendência italiana e originários das "colônias". Nenhum deles tinha na escrita sua atividade profissional ou mesmo principal, tratando-se de pessoas sem formação específica nessa área, mas "interessadas" pela "história" e a "cultura" dos imigrantes. ${ }^{11}$ Em muitos casos, como nos relatou, frei L. lhes sugeria qual assunto "pesquisar", geralmente segundo o grau de familiaridade ou a proximidade de que dispunham, como por exemplo, na elaboração das "histórias locais", na qual os autores escrevem sobre sua "região" de origem ou então aquela onde vivem. De fato, um dos expedientes de "pesquisa" mais comuns era a coleta de material, tais como depoimentos, fotografias, genealogias e documentos variados, entre os próprios familiares dos autores - ou então de populações de suas comunidades de origem - para, então, se apresentarem uma série de narrativas sobre "histórias familiares" desses imigrantes e descendentes, suas "memórias" e visões da imigração e de sua forma de viver no novo ambiente.

Dessa forma, era dado início a um vasto "projeto" de revalorização social do "mundo comunitário", do qual esses indivíduos haviam saído e agora estavam em condições de fazer ser reconhecido através de instrumentos importantes de legitimação social, tendo por base, de um lado, recursos culturais e escolares adequados 
às tarefas de "falar" sobre a "cultura italiana" (formação humanística e letrada, "conhecimento" dos costumes, do ethos, do dialeto, da religião etc.) e, de outro, um capital de relações em que a ligação com a instância editorial tinha peso acentuado. É assim, portanto, que esse grupo de descendentes de imigrantes e oriundos das pequenas comunidades rurais poderá acionar todo um repertório étnico-cultural e religioso, assentado em uma mesma matriz, que trata de consagrar o estilo de vida daquele meio social, percebido em "desvantagem" frente ao celebrado progresso urbano-industrial das cidades. Tratando de redimensionar as percepções sobre o "universo colonial" a partir de sua "reconstituição", é a "história" e o "saber" dos "colonos" que serão objeto de abrangente inventário de parte desses "pesquisadores", desde os dialetos, o folclore, as estórias e a literatura, a religiosidade, a arquitetura, enfim, um conjunto de atributos identitários de que se ocuparão para, nas palavras de frei L., "fortalecer a consciência de italianidade e a caracterização do típico modo de ser italiano no Rio Grande do Sul".

Quase todos são escritos rurais ou familiares. São autores que se dão conta do paraíso perdido e querem salvar os valores que percebem como importantes. Há um desejo do urbano que quer devolver ao rural um agradecimento, como professor ou religioso. Há aí uma ingenuidade, uma simplicidade, um lado afetivo. Então vêm as histórias, as estórias e fròtole.

No entanto, um elemento central para a consolidação e o "êxito" desse empreendimento foi a parceria estabelecida por frei L. com um "amigo próximo", ex-capuchinho ${ }^{12}$, detentor de recursos escolares e culturais reconhecidos e com inserção estratégica na esfera universitária. "Solicitado" por frei L. a se engajar na pesquisa e divulgação de escritos no campo da imigração, esse professor de filosofia, à época trabalhando na Universidade de Caxias do Sul como professor e, por algum tempo, também diretor da editora 
"Intérpretes da história e da cultura": carreiras religiosas...

da instituição, facilitaria não somente o reconhecimento das publicações naquela área, mas também a importante aproximação com o universo escolar. Em primeiro lugar, pode-se mencionar o fato de ter introduzido e divulgado o livro "inaugural" de frei L. naquela universidade ao utilizá-lo como base para a disciplina de Estudos de Problemas Brasileiros que ministrou.

Porém, o aspecto mais relevante se refere, sem dúvida, à associação das duas editoras em um longo empreendimento destinado a produzir um acervo bibliográfico que "desse conta da imigração". Através de uma grande quantidade de co-edições entre as editoras dirigidas pelos dois ex-confrades, pesquisadores de carreira universitária (historiadores, sociólogos, antropólogos, especialistas em literatura e lingüística etc.), sacerdotes e ex-religiosos dividiriam o mesmo espaço para a divulgação de obras de caráter bastante heterogêneo. Pelo lado da universidade, o Instituto Superior Brasileiro-Italiano de Estudos e Pesquisas ${ }^{13}$ representaria um ponto de articulação importante com instâncias intelectuais em nível não apenas estadual, permitindo o contato com especialistas acadêmicos e a integração daqueles principais "religiosospesquisadores" em circuitos de relações pessoais e institucionais marcados por um maior profissionalismo e legitimidade escolares. A participação daqueles dois religiosos em eventos acadêmicocientíficos, a publicação em periódicos ou em coletâneas juntamente com pesquisadores "de ofício" e, em pouco tempo, os numerosos convites para dirigir e organizar obras sobre a imigração, enfim, seu reconhecimento como "especialistas", também deveriam muito ao crescente envolvimento em meios intelectuais valorizados.

Uma boa demonstração dessa rápida integração aos círculos acadêmicos pode ser encontrada na participação dos dois "religiosos-editores" em pauta nos fóruns sobre imigração italiana ocorridos em Caxias do Sul em 1975 e 1976, a cargo do Instituto Superior Brasileiro-Italiano de Estudos, e cujos anais foram publicados sob o título Imigração Italiana: estudos. Entre os participantes, figura 
uma grande gama de pesquisadores gaúchos e do centro do país, sobretudo historiadores e sociólogos, muitos deles gozando de grande notabilidade dentro de suas "especialidades". Porém, um exemplo ainda mais significativo do acúmulo de notoriedade daqueles religiosos e do uso de relações entretidas com instâncias culturais foi sua participação destacada em um conjunto de simpósios sobre "a presença italiana no Brasil", realizado ao longo de três eventos sediados em capitais brasileiras entre meados dos anos $80 \mathrm{e}$ início dos 90, promovido por uma grande fundação italiana voltada à promoção da cultura italiana no exterior. Desse modo, além de organizar e coordenar as conferências, foram responsáveis pela publicação de três volumes com os textos apresentados por dezenas de "pesquisadores" e "intelectuais", quase todos ligados a universidades, e muitos deles com projeção nacional. Por "esforço" do editor capuchinho, as três volumosas obras vieram a público em co-edições com a fundação italiana, fazendo parte da coleção Imigração Italiana", a qual, já em 1990, chegava ao centésimo título. Ao lado de tais publicações e atividades relacionadas, em maior ou menor grau, com a esfera acadêmica, outro indicador do acionamento do capital de relações desses intelectuais dentro das condições de sua ascensão são os vários "convites de amigos" para coordenar trabalhos de caráter celebrativo na temática da "cultura italiana", como os "álbuns" e livros comemorativos da imigração. ${ }^{14}$ Assim, durante o ano em que foi celebrado o $125^{\circ}$ aniversário da imigração, frei L., já então membro do Conselho Estadual de Cultura há muitos anos, foi encarregado de fazer o discurso de abertura das festividades, também editando, ao longo daquele mesmo ano, 34 livros ligado ao assunto.

"Interpreters of History and Culture": religious careers and cultural mediation in the State of Rio Grande do Sul

Abstract: This work examines the patterns of constitution and exercise of the role of cultural mediation by Catholic-committed individuals in the Southern Brazilian State of Rio Grande do Sul. Focused on the second half of the $20^{\text {th }}$ century, it 
"Intérpretes da história e da cultura": carreiras religiosas...

analyses the specific circumstances of formation of "experts/interpreters" in "culture" and "history" of the Italian and German immigrant groups in the region, whose works are mainly devoted to celebrate both the social attributes and the ascension of the groups they represent. Besides the analysis of the school and cultural assets accumulated by these mediators in different social spheres (religious, scientific/academic, intellectual, artistic), it also casts light on the symbolic instruments (publications, institutes, study centres, posts, homage, publishing houses) forged in the disputes of interpreting the immigrant ethnical groups. The study also seeks to contribute to the field of analysis of immigration and colonization phenomena (not only in the State of Rio Grande do Sul) through relativizing social representations based on notions taken from disciplines such as History, Social Sciences and Philosophy which have been largely incorporated by the academic common-sense.

Keywords: Cultural Mediation. Immigration. Catholicism. Intellectuals. 
Anexo:

Quadro I - Padres, religiosos e leigos professores:

formação superior, especialização, cursos

Tipo curso/Instituição

$\mathrm{N}=\mathrm{B}$

Especialização

O4

Mestrado

12

Doutorado 11

Pós-Doutorado

O1

Estudos não -religiosos

@

Outros cursos

$\mathrm{OR}$

Área estudo religioso

Teologia

16

Direito Canônico

OI

História Eclesiástica

OR

Moral

N-

Liturgia

Ñ-

Gências da Religião

Or

Arte Sacra

or

Área estudo profano

Letras

OI

Filosofia

OR

Educação

O4

Pedagogia

O4

Mísica

Or

Fonte: Dados coletados pelo autor. 
"Intérpretes da história e da cultura": carreiras religiosas...

\section{Notas:}

${ }^{1}$ Sobre essas questões, consultar os trabalhos de Seyferth (1982 e 1986) centrados numa região de imigração alemã no Estado de Santa Catarina. Com respeito ao papel de mediadores culturais envolvidos na interpretação dos grupos étnico da imigração "italiana”, ver Coradini (1998a).

${ }^{2}$ A esse respeito, consultar Seidl (2003), seção 2.2, “Origens étnicas e geografia da religião".

${ }^{3}$ Desses, dois deixaram a condição religiosa, porém mantendo-se intimamente vinculados à Igreja.

${ }^{4}$ Seu irmão mais velho, também padre jesuíta e "botânico" renomado, trabalhara nessa instituição por vários anos e fora um dos fundadores da "cátedra de antropologia". Além de uma "carreira" dedicada às ciências naturais, esse sacerdote consagrou-se como um dos principais representantes da restauração católica liderada pela Companhia de Jesus no Rio Grande do Sul na primeira metade do século XX.

${ }^{5}$ As possibilidades de acesso desses religiosos à principal universidade pública do Estado na condição de profissionais indicam não somente o peso do capital de relações por eles detido no âmbito universitário, mas também a valorização dos recursos culturais (relativamente raros à época) que possuíam.

${ }^{6}$ De modo mais geral, as possibilidades de reconversão de recursos culturais adquiridos em instituições religiosas (conventos, institutos, seminários menor e maior, graduação em filosofia e teologia etc.) na realização de uma variedade de carreiras profissionais leigas (ligadas ou não à Igreja) configuram alternativas concretas a indivíduos dispondo de determinadas competências e disposições rentáveis nas áreas de domínio das "humanidades", tais como atividades em educação, ensino e pesquisa (professor, educador, pedagogo, pesquisador), em psicologia e em tarefas de administração de recursos humanos. Para detalhes sobre as relações entre o saber religioso e os saberes "exógenos" e seus usos por agentes religiosos, profissionais da saúde e especialistas das relações humanas, ver Déconchy (1985).

${ }^{7}$ Ver, por exemplo, a introdução à obra Imigração italiana no Rio Grande do Sul: vida, costumes e tradiçôes, na qual é apresentado esse tipo de "posicionamento teórico". Cf. Costa et al. (1975).

${ }^{8}$ Dentre essas formas de publicação, citamos os impressos institucionais Informativo da Provincia Sul-Brasileira e Notíciaspara Nossos Amigos, e os jornais Gazeta do Sul (Sta. Cruz do Sul), Correio do Povo (Porto Alegre), Serra-Post Kalender (Iju1), Cadernos de Blumenau (Santa Catarina) e Hans Staden Jahrbuch (São Paulo). Ver mais a respeito em Bohnen, A.; Ullmann, A. (1989: 346-347).

Anos 90, Porto Alegre, v. 14 n. 26, p. 77-110, dez. 2007 


\section{Ernesto Seidl}

${ }^{9}$ Sobre essa e outras modalidades de produção biográfica e autobiográfica de caráter institucional como estratégia de ascensão na carreira, ver o cap. II do livro de Sérgio Miceli (1988) dedicado à discussão de fontes para o estudo de elites religiosas no Brasil.

${ }^{10} \mathrm{Na}$ condição de "especialista" sobre o "mundo italiano" no Rio Grande do Sul, frei L. é solicitado a dar entrevistas com muita freqüência. Ao nos apresentarmos para nossa primeira entrevista, perguntou se havíamos visto seus depoimentos em reportagem televisiva veiculada pouco tempo antes na qual falava sobre a "etnia" italiana. Da mesma forma, sua "trajetória" foi matéria de seção especial dedicada a "grandes depoimentos", publicado no principal jornal do Estado. Nela, o religioso é apresentado como "um dos mais significativos personagens da vida cultural e intelectual do Rio Grande”, destacado por "conduzir com sucesso uma série de atividades paralelas: a de líder religioso voltado ao trabalho pastoral, a de infatigável editor de livros, pesquisador da imigração italiana, bibliófilo e professor universitário". ${ }^{11}$ A única exceção de que tivemos conhecimento é o caso de um frade capuchinho, neto de italianos e diretamente ligado a frei L., o qual nos últimos anos tem-se dedicado em tempo quase integral a pesquisar e escrever sobre a imigração, sua atuação de cunho "pastoral" reduzindo-se à assistência em uma paróquia de Porto Alegre aos sábados e domingos. No início da década de 1980, publicou em conjunto com frei L. um volumoso trabalho, editado em dois tomos com formato de álbum, farto em documentos e fotos retratando o "mundo colonial", dentro da coleção Imigração Italiana. Como "prêmio" por essa obra, os dois sacerdotes receberam bolsas de estudos de uma fundação cultural italiana para "pesquisar" na Itália.

${ }^{12}$ Uma noção das categorias identificadas na elaboração da memória mítica dos descendentes de imigrantes italianos no Rio Grande do Sul é apresentada no artigo Mocellin (1996), intitulado "Itália: o elo rompido agora reatado".

${ }^{13}$ Trata-se do outro sacerdote capuchinho referido na primeira parte dessa seção, e que viria a deixar a ordem religiosa.

${ }^{14}$ No bojo desse instituto, foi criado no final da década de 1970 um projeto de "pesquisa" dedicado a estudar os "elementos culturais nas colônias italianas", plano que se desdobraria em diversas áreas tanto de investigação quanto de promoção cultural. Cf. Ribeiro (1996).

${ }^{15}$ Entre os principais “amigos” de frei L., e responsável por muitas de suas "indicações" e "convites", está o já mencionado filho do cônsul italiano em Garibaldi. Advogado, escritor, e crítico literário, esse "intelectual", membro da Academia RioGrandense de Letras, ocupa posição estratégica nos círculos de instituições "italianistas" no Rio Grande do Sul.

Anos 90, Porto Alegre, v. 14 n. 26, p. 77-110, dez. 2007 
"Intérpretes da história e da cultura": carreiras religiosas...

\section{Referências:}

ANJOS, José Carlos G. dos. Intelectuais, literatura e poder em Cabo Verde: lutas de definição da identidade nacional. Porto Alegre: Editora da UFRGS, 2006.

BATTISTEL, Arlindo I.; COSTA, Rovílio. Assim vivem os italianos: vida, história, cantos, comidas e estórias. Porto Alegre/Caxias do Sul: EST/EDUCS, v. I, 1982.

. COSTA, Rovílio. Assim vivem os italianos: religião, música, trabalho e lazer. Porto Alegre/Caxias do Sul: EST/EDUCS, v. II, 1983.

Colônia italiana: religião e costumes. Porto Alegre: EST, 1981.

BOHNEN, Aloysio.; ULLMANN, Reynholdo A. A atividade dos jesuitas de São Leopoldo (1844-1989). São Leopoldo: UNISINOS, 1989.

BOURDIEU, Pierre. Homo Academicus. Paris: Minuit, 1984.

CATÁLOGO de Publicações da Editora UNISINOS, 2002-2003.

CATÁLOGO de Publicações da Escola Superior de Teologia - EST Edições, abril 2001; novembro 2002 (série "Etnias e Culturas").

CLEMENTE, Elvo. Pilares da PUCRS. Porto Alegre: EDIPUCRS, 2001.

CORADINI, Odaci L. Os significados da noção de "italianos", In: MAESTRI, Mário (coord.). Nós, os italo-gaúchos. Porto Alegre: Editora da Universidade/UFRGS, 2. ed., 1998a.

. Origens sociais, mediação e processo eleitoral em um município de imigração italiana. In: BARREIRA, Irlys; PALMEIRA, Moacir (orgs.). Candidatos e Candidaturas: Enredos de Campanha Eleitoral no Brasil. São Paulo: Annablume, 1998b.

"Grandes famílias" e elite "profissional” na Medicina no Brasil. In: Cadernos de Ciência Politica, Porto Alegre, n. 2, UFRGS, 1995.

COSTA, Rovílio. A imigração italiana: minha paixão de cada dia. In: Chronos, Caxias do Sul, v. 29, n. 1, jan./jun., p. 107-110, 1996.

Culto à Maria entre descendentes de italianos no Rio Grande do Sul, In: DE BONI, Luís A. (org.) A presença italiana no Brasil. V. II Porto Alegre/Torino: EST/Fondazione Giovanni Agnelli, 1990.

Filó, uma experiência de paraíso, In: MAESTRI, Mário (coord.). Nós, os italo-gaúchos. Porto Alegre: Editora da Universidade/UFRGS, 2. ed.,1998, p. 178180.

COSTA, Rovílio et al. A imigração no Rio Grande do Sul: vidas, costumes e tradições. Porto Alegre: EST, 1975.

Anos 90, Porto Alegre, v. 14 n. 26, p. 77-110, dez. 2007 


\section{Ernesto Seidl}

. Antropologia visual da imigração italiana. Porto Alegre: EST: 1976.

COSTA, Rovílio; MARCON, Itálico. Imigração italiana no Rio Grande do Sul: fontes históricas. Porto Alegre/Caxias do Sul: EST/EDUCS, 1988.

COSTA, Rovílio; DE BONI, Luís A. "Nós, os gringos”. In: MAESTRI, Mário (coord.). Nós, os italo-gaúchos. Porto Alegre: Editora da Universidade/UFRGS, 2. ed., 1998, p. 18-23. 1996.

DE BONI, Luís A. Os capuchinhos do Rio Grande do Sul. Porto Alegre: EST,

DE BONI, Luís A. Os italianos do Rio Grande do Sul. Porto Alegre/Caxias do Sul: EST/EDUCS, 3. ed., 1984.

DE BONI, Luís A. (org.) A presença italiana no Brasil. V. I, II e III. Porto Alegre/ Torino: EST/Fondazione Giovanni Agnelli, 1987, 1990 e 1996.

. Catolicismo no Brasil: início do fim? Caxias: Universidade de Caxias do Sul/ Porto Alegre: EST, 1977.

DE BONI, Luís A.; COSTA, Rovílio. Far la Mérica: a presença italiana no Rio Grande do Sul/Making it in América: the Italian presence in Rio Grande do Sul. Porto Alegre: Riocell, 1991.

DE BONI, Luís A. O Catolicismo da Imigração: do triunfo à crise. In: DACANAL, José Hildebrando. RS: Imigração e Colonizaçãa. Porto Alegre: Mercado Aberto, 1980, p. 234-255.

DECONCHY, Jean-Pierre. Savoirs religieux, contrôle religieux et appropriation des savoirs "exogènes": quelques axes de réflexion et de recherche. In: VINCENT, Gilbert; RÉMY, Jean; DECONCHY, Jean-Pierre. Les nouveaux clercs: prêtres, pasteurs et spécialistes des relations humaines et de la santé. Genève: Labor \& Fides, 1985. p. 63-86.

LUTTERBECK, Jorge A. Jesuitas no sul do Brasil. São Leopoldo: Instituto Anchietano de Pesquisas, 1977.

MANFROI, Olívio. A colonização italiana no Rio Grande do Sul: implicações econômicas, políticas e culturais. Porto Alegre: EST, 2. ed., 2001.

MICELI, Sérgio. A elite eclesiástica brasileira. Rio de Janeiro: Bertrand Brasil, 1988.

MOCELLIN, Maria C. Itália: o elo rompido agora reatado. In: Chronos, v. 29, n. 1, 1996. p. 82-87.

RABUSKE, Arthur. A nacionalização e a Igreja católica. In: MÜLLER, Telmo L. Nacionalização e imigração alemã. São Leopoldo: UNISINOS, 1994. p. 157-188.

- Os inícios da colônia italiana no Rio Grande do Sul em escritos de jesuitas alemães. Porto Alegre/Caxias do Sul: EST/EDUCS, 1978.

Anos 90, Porto Alegre, v. 14 n. 26, p. 77-110, dez. 2007 
"Intérpretes da história e da cultura": carreiras religiosas...

Os inícios da República brasileira e a Igreja Católica. In: Revista do Instituto Histórico e Geográfico do Rio Grande do Sul, Porto Alegre, n. 126, p. 117-140, 1989.

. Os nossos três mártires recém-canonizados. In: Cadernos do IHERGS, n. 2, p. 3-13, 1989.

Nova fisionomia da Igreja no Rio Grande do Sul, a partir de 1850. In: Renovação, Porto Alegre, CNBB Regional Sul-3, n. 122, nov, 1978. p. 15-20.

Os "Bruder" jesuítas no sul do Brasil: alguns esboços biográficos. In: Separata dos Anais do $1^{\circ}$ Simpósio de História da Imigração e Colonização Alemã no Rio Grande do Sul, s.d.

RIBEIRO, Cleodes M. P. J. A cultura da imigração italiana. In: Chronos, Caxias do Sul, v. 29, n. 1, jan./jun. 1996, p. 101-104.

SANTIN, Silvino. A imigração esquecida. Porto Alegre: EST, 1986.

SEYFERTH, Giralda. A representação do 'trabalho alemão' na ideologia étnica teuto-brasileira. In: Boletim do Museu Nacional, Rio de Janeiro, Nova Série Antropologia, n. 37, out. 1982, p. 1-33.

. Imigração, colonização e identidade étnica (notas sobre a emergência da etnicidade em grupos de origem européia no sul do Brasil). In: Revista de Antropologia, São Paulo, v. XXIX, 1986, p. 58-71.

SILVERMAN, S. F. The community-nation mediator in traditional central-Italy. In: SHANIN, T. (edit.). Peasants and peasant societies: selected readings. Harmondsworth: Penguin books, 1971.

UNISINOS. Relatório de Atividades - 2001. São Leopoldo: UNISINOS, 2001.

VINCENT, Gilbert. Sociologie de la cléricature: objets et problèmes. In: VINCENT, Gilbert, RÉMY; Jean.; DECONCHY, Jean-Pierre. Les nouveaux clercs: prêtres, pasteurs et spécialistes des relations humaines et de la santé. Genève: Labor \& Fides, 1985, p. 11-40.

ZAGONEL, Carlos A. Capuchinhos no Brasil. Porto Alegre: EST, 2001.

Igreja e imigração italiana. Porto Alegre: EST, 1975.

WOLF, E. Aspects of group relations in a complex society: Mexico. In: SHANIN, T. (edit.). Peasants and peasant societies: selected readings. Harmondsworth: Penguin books, 1971.

Recebido em 28/09/2007.

Aprovado em 22/10/2007.

Anos 90, Porto Alegre, v. 14 n. 26, p. 77-110, dez. 2007 